\title{
PENGGUNAAN KONJUNGSI TOKI, TOKI(NI), TOKI (NI) WA DALAM KALIMAT BAHASA JEPANG
}

\author{
Elizabeth Ika Hesti Aprilia Nindia Rini \\ Program Studi Bahasa dan Sastra Jepang FIB Universitas Diponegoro \\ Email: eliz_ikahesti@yahoo.co.id
}

\begin{abstract}
Conjunction toki indicates time relation that expreesses actions that occur at the same time. Toki has three variants, they are toki, toki (ni), and toki (ni) wa. Each of them has its speciality of usage. Toki is the most neutral of all. The usage of particle (-ni) and (-ni) wa affects to the usage of toki in a sentence. Toki (ni) is used to express actions that happen one time, while toki (ni) wa expresses an general actions.
\end{abstract}

Keywords : conjuction toki, toki (ni), toki (ni) wa, hakken, new and old information.

\section{PENDAHULUAN}

Klausa temporal adalah klausa subordinatif yang mewatasi waktu terjadinya aktivitas atau keadaan yang terdapat pada klausa utama dikaitkan dengan peristiwa lain (Nitta, 2008:165). Hubungan waktu ini ditentukan oleh penghubung antarklausa. Toki merupakan konjungsi yang menunjukkan bahwa aktivitas atau keadaan pada klausa temporal dan klausa utama terjadi dalam waktu yang sama.

Hubungan waktu (taksis) antarklausa yang dihubungkan oleh konjungsi toki ini merupakan permasalahan yang menarik untuk dibahas, terutama bagi pembelajar bahasa Jepang di Indonesia yang tidak memiliki penanda aspek secara gramatikal. Hal ini telah dibahas dalam Taksis Subordinatif pada Kalimat Majemuk Bahasa Jepang dengan Setsuzokujoshi Toki (Rini, 2013). Oleh karena itu pada kesempatan ini akan dibahas lebih lanjut mengenai bagaimanakah karakteristik kalimat yang dihubungkan oleh toki terkait dengan partikel yang melekatinya.

\section{ISI}

Menurut Teramura (1999:155) terdapat tiga jenis struktur kalimat yang dihubungkan oleh konjungsi toki yaitu $\mathrm{P}$ toki $\mathrm{Q}, \mathrm{P}$ toki ni $\mathrm{Q}$, dan $\mathrm{P}$ toki (ni) wa $\mathrm{Q}$, di mana $\mathrm{P}$ merupakan frasa atau klausa temporal yang mewatasi aktivitas atau keadaan Q, dan Q menyatakan klausa utama.

Berikut ini adalah paparan mengenai karakteristik masing-masing sruktur kalimat yang dihubungkan dengan konjungsi toki.

\subsubsection{Konstruksi P Toki Q}

Menurut Masuoka, konstruksi P toki Q yang tidak dilekati partikel ( $\varnothing)$ ini, memiliki karakteristik sama dengan keterangan waktu（時間表現 / jikan hyougen) dalam kalimat bahasa Jepang yang tidak dilekati partikel (-ø) (Nitta, 1997:153). Seperti pada contoh kalimat berikut ini.

（1） 10 年前、私はあることを決意し た の だ

(Nitta, 1997:154)

Juu nen mae / watashi / wa / aru koto /o / ketsui shita / noda.

Sepuluh tahun lalu / saya / PT / suatu hal / PO / memutuskan / Vbm.

'Sepuluh tahun lalu saya memutuskan sesuatu.'

(2) 友達を待っているあいだこの本 を読んでいた。 (Nitta, 1997:155)

Tomodachi / o / matteiru

aida / kono / hon /o / yondeita.

Teman / PO / sedang menunggu / selama

/ ini / buku / PO / sedang membaca.

'Selama menunggu teman, (saya) sedang membaca buku ini.' 
(3) 京都の古本屋に行ったとき思い がけない本を見つけた。 (Nitta, 1997:149)

Kyouto / no / furuhonya / ni / itta /

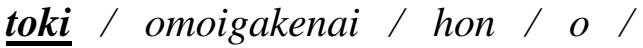
mitsuketa.

Kyoto / PNN / toko buku bekas / PL / pergi / KT / tidak terduga / buku/ PO/menemukan.

'Ketika pergi ke toko buku bekas di Kyoto, (saya) menemukan buku yang tidak

terduga.'

Pada konstruksi kalimat (1), (2), dan (3) terdapat kesamaan fungsi ungkapan waktu ( 時間表現 / jikan hyougen) yang tidak dilekati partikel $(-\varnothing)$, "sepuluh tahun yang lalu” (10 年前 / juu nen mae) pada kalimat (1), “selama menunggu teman” (友達を待 つているあいだ / Tomodachi o matteiru aida) pada kalimat (2), dan "ketika pergi ke toko buku bekas di Kyoto” (京都の古本屋 に行ったとき/ Kyouto no furuhonya ni itta toki), yaitu untuk menetapkan latar waktu (時間の設定 / jikan no settei), guna mendeskripsikan peristiwa dalam suatu kalimat. Pada kalimat (3) misalnya, pertama-tama ditetapkan latar waktu "ketika pergi ke toko buku bekas di Kyoto" (京都の 古本屋に行ったとき / Kyouto no furuhonya ni itta toki), kemudian dipaparkan peristiwa yang terjadi “menemukan buku yang tidak terduga." (思 いがけない本を見つけた / omoigakenai hon o mitsuketa ) pada waktu yang telah ditetapkan tersebut. Fungsi seperti ini disebut sebagai komponen keadaan (状況成 分 / joukyou seibun).

Kalimat dalam bahasa Jepang sendiri terdiri atas beberapa komponen, diantaranya adalah komponen keadaan (状況成分 / joukyou seibun). Komponen keadaan adalah bentuk yang digunakan untuk menunjukkan keadaan dan latar eksternal terjadinya peristiwa, seperti waktu, tempat, dan penyebab, berdasarkan komponen predikat ( 述語成分 / jutsugo seibun), komponen koeksis (共演成分 / kyouen seibun), dan komponen modifikator dalam proposisinya (
命題内修飾成分 / meidainai shuushoku seibun) (Nitta, 2002:25). P toki Q termasuk komponen keadaan yang menyatakan waktu.

Sementara itu, menurut Teramura (1999:155) konstruksi P toki Q, baik P (yang menyatakan peristiwa pada klausa temporal) maupun Q (yang menyatakan peristiwa pada klausa utama), masing-masing menyatakan informasi baru. Konstruksi seperti ini banyak digunakan pada kalimat yang memaparkan berkembangnya peristiwa satu per satu seiring dengan berjalannya (mengalirnya) alur waktu seperti pada dongeng mukashi banashi.

Menurut Masuoka dalam Nitta (1997:151), tidak adanya gayutan partikel ($\varnothing)$ pada konjungsi toki berpengaruh pada fungsi pemfokusan (焦点化 / shoutenka) dalam kalimat. Hal ini bersifat umum dan tidak hanya berlaku pada konstruksi kalimat majemuk yang dihubungakan oleh toki saja. Ungkapan waktu pada kalimat (1), (2), dan (3) yang menggunakank konjungsi toki sebagai penghubung antarklausa tidak dapat dijadikan fokus dalam kalimat. Untuk mengamati fokus dalam kalimat, kalimat (1) dipermutasikan menjadi (1'), dan diketahui bahwa kalimat (1) tidak bisa diinterpretasikan menjadi kalimat (1'), karena pada kalimat dimana ungkapan waktunya tidak digayuti oleh partikel $(-\varnothing)$ tidak terdapat fokus kalimat.

(1’) 私があることを決意したのは、 10 年前 / だ。 1997:154)

Watashi / ga / aru koto / o / ketsui shita / no / wa /juu nen mae / da. Saya / PS / suatu hal / PO / memutuskan / Nom / PT / sepuluh tahun lalu / Kop.

'Saat saya memutuskan sesuatu itu adalah sepuluh tahun lalu.'

Hal ini disebabkan karena komponen keadaan (状況成分 / joukyou seibun) memberikan informasi yang berkaitan dengan waktu sebagai dasar pemikiran untuk memaparkan peristiwa berikutnya. Dan pada kasus seperti ini, klausa toki merupakan unsur luar dari bagian yang memaparkan peristiwa (事態を叙述する部 分の外部要素 / jitai o jujutsu suru bubun no gaibu yousou). Selain itu, karena 
ungkapan waktu tanpa gayutan partikel (- $\varnothing)$ tidak mempunyai lingkupan penegas (主張 のスコープ / shuchou no sukoopu) maka tidak dapat dijadikan fokus penegas.

Kontruksi $\mathrm{P}$ toki $\mathrm{Q}$ umumnya digunakan pada kalimat dimana pertamatama diungkapkan kejadian atau peristiwa $\mathrm{P}$ terlebih dahulu, kemudian berikutnya dipaparkan peristiwa $\mathrm{Q}$ sebagai peristiwa yang terjadi selanjutnya mengikuti peristiwa $\mathrm{P}$, sebagai kemunculan (発見 / hakken) seperti terlihat pada kalimat berikut ini.

(4)「あなた」

"Anata."

"Sayang."

よりこひばち

頼子が火鉢の向こうで言った。

すわっている二人の距離は遠か

った。

"Yoriko / ga / hibachi / no / mukou / de / itta. I Suwatteiru / futari / no / kyouril

"Yoriko / PS / pendiangan / PNN / seberang / PL / berkata / Sedang duduk / berdua / $\mathrm{PNN} /$ jarak /

結城が雑誌から目を上げたとき、 頼子さんはきちんとすわってい た。

Yuuki / ga /zasshi / kara / me / o /ageta / toki, / Yuriko / wa / kichinto / suwatte ita.

Yuuki / PS / majalah / dari / mata / PO / mengangkat / KT, / Yoriko / PT / dengan rapi / sedang duduk.

"“Sayang."

Kata Yuriko di seberang pendiangan. Mereka berdua duduk berjauhan. Ketika Yuki mengangkat matanya dari majalah, Yuriko sedang duduk dengan rapi.'

(Matsumoto Seichou "Nami no Tou" "Menara Ombak") dalam (Teramura, 1999:152)
Konjungsi toki tanpa gayutan partikel (- $\varnothing)$ pada konstruksi $\mathrm{P}$ toki $\mathrm{Q}$ merupakan penghubung yang paling netral bila dibandingkan varian yang lainnya, karena dapat digunakan untuk menyulih konjungsi toki dengan gayutan partikel kasus (-ni) dan konjungsi toki dengan gayutan partikel pemarkah topik (-wa).

(5) 子どものときに（とき）、よく 川でザリガニをとつた。

(Ichikawa, 2005 : 398)

Kodomo / no / toki ni (toki), lyoku / kawa / de / zarigani / o / totta.

Anak-anak / PNN / KT PW (KT) / sering / sungai / di / udang pancang / PO / mengambil.

'Ketika anak-anak, (saya) sering mengambil udang pancang di sungai.'

(6) 子どものときは（とき）、みん ないたずらで楽しかった。

(Ichikawa, $2005: 398$ )

Kodomo / no / toki wa (toki), / minna / itazura de /tanoshikatta. Anak-anak / PNN / KT PT (KT), semua / nakal dan / senang.

'Ketika anak-anak, semua nakal dan senang.'

Konjungsi toki (ni) pada kalimat (5) maupun konjungsi toki (wa) pada kalimat (6) dapat disulih dengan konjungsi toki.

\subsubsection{Konstruksi P Toki ni Q}

Konstruksi kalimat $\mathrm{P}$ toki ni $\mathrm{Q}$, digunakan untuk mengungkapkan jawaban atas pertanyaan kapan peristiwa Q itu terjadi.

Karakteristik partikel (-ni) dalam kalimat yang dihubungkan dengan konjungsi toki, secara umum juga memperlihatkan kesamaan dengan konstruksi kalimat bahasa Jepang pada ungkapan waktu (時間表現 / jikan hyougen) yang dilekati dengan partikel (-ni) (Nitta, 1997:153). Gayutan partikel kasus (-ni) pada ungkapan waktu berfungsi untuk menyatakan waktu yang spesifik. Berikut ini adalah kalimat dengan ungkapan waktu yang digayuti partikel (-ni). 
(7) 7 月 4 日に生まれたのだ。 (Nitta, 1997:153)

Shichi gatsu yokka / ni / umareta /

noda.

Vbm.

Tanggal 4 Juli / $\quad$ /

'(Saya) lahir pada tanggal 4 Juli.'

(8) 友達を待っているあいだにこの 考えを思い付いたのだ。

(Nitta, 1997:155)

Tomodachi / o / matteiru / aida ni/ kono / kangae / o / omoitsuita / noda.

Teman / PO / menunggu / selama / ini / gagasan / PO / mendapat / Vbm.

'Selama menunggu teman, (saya) mendapat gagasan ini.'

(9) 京都の古本屋に行ったときにこ の本を見つけたのだ。 (Nitta, 1997:150)

Kyouto / no / furuhonya / ni / itta / toki ni / kono / hon / o / mitsuketa / noda. Kyoto / PNN / toko buku bekas/PL / pergi / KT-PW / ini / buku/PO/menemukan / Vbm.

'Ketika pergi ke toko buku bekas di Kyoto, (saya) menemukan buku ini.'

Pada kalimat (7), (8), dan (9), ungkapan waktu (時間表現 / jikan hyougen) “pada tanggal 4 Juli” (7 月 4 日に / Shichi gatsu yokka ni) pada kalimat (7), “selama menunggu teman” (友達を待っているあい だに / Tomodachi o matte iru aida ni) pada kalimat (8), dan "ketika pergi ke toko buku bekas di Kyoto” (京都 の古本屋に行った ときに / Kyouto no furuhonya ni itta toki ni ) pada kalimat (9) yang digayuti oleh partikel kasus (-ni), memiliki kesamaan fungsi yaitu menentukan waktu (時間の特 定 / jikan no tokutei) terjadinya peristiwa.

Pada kalimat (9) dinyatakan bahwa waktu terjadinya Q "(saya) menemukan buku ini" adalah $\mathrm{P}$ "ketika pergi ke toko buku bekas di Kyoto". Pada konstruksi kalimat ini, Q merupakan informasi lama (sudah diketahui lebih dahulu baik oleh pembicara maupun lawan bicara), dan yang menjadi permasalahan adalah kapan terjadinya peritiwa $\mathbf{Q}(\lceil\mathrm{Q}$ という事態が いつ起こつたか」/“Q to iu jitai ga itsu okotta $k a$ "). Hal seperti ini disebut sebagai fungsi komponen partikel kasus (格成分 / kaku seibun). Komponen partikel kasus secara umum mempunyai fungsi menentukan informasi mengenai suatu peristiwa, pada partikel - $n i$ partikel kasus mempunyai fungsi mewatasi adanya peristiwa (事態のあり方を限定する / jitai no arikata o gentei suru).

Menurut Masuoka dalam Nitta (1997:151), gayutan partikel kasus (-ni) pada konjungsi toki berpengaruh pada fungsi pemfokusan (焦点化 / shoutenka) dalam kalimat. Hal ini merupakan hal yang bersifat umum dan tidak hanya terlihat pada konstruksi kalimat majemuk yang dihubungakan oleh konjungsi toki saja. Ungkapan waktu pada kalimat (7), (8), dan (9) yang mengandung konjungsi toki yang digayuti partikel kasus (-ni) dapat dijadikan fokus dalam kalimat.

Untuk mengamati fokus dalam kalimat, kalimat (9) dipermutasikan menjadi (9'), diketahui bahwa kalimat (9) bisa diinterpretasikan menjadi kalimat (9'), karena pada kalimat yang ungkapan waktunya digayuti oleh partikel kasus (-ni), terdapat fokus kalimat.

(9’)この本を見つけたのは、京都の 古本屋に行ったときだ。 1997:150)

Kono / hon / o / mitsuketa / no / wa / Kyouto / no / furuhonya / ni / itta / toki / da.

Ini / buku / PO / menemukan / Nom / PT / Kyoto / PNN / toko buku bekas / PL / pergi / $\underline{\text { KT / }}$ Kop.

'(Saya) menemukan buku ini ketika pergi ke toko buku bekas di Kyoto.'

Hal ini disebabkan karena komponen partikel kasus (格成分 / kaku seibun) (-ni) berperan mewatasi waktu peristiwa klausa utama. Dengan kata lain, dapat dilihat sebagai unsur bagian dalam dari paparan peristiwa (事態を叙述する部分の内部要 素 / jitai o jujutsu suru bubun no naibu youso). Pada kalimat (9) “(saya) menemukan buku ini” (この本を見つけた। kono hon o mitsuketa) sebagai topik kalimat, memberikan penegasan bahwa waktu terjadinya peristiwa adalah "ketika pergi ke toko buku bekas di Kyoto” (京都の 古本屋に行ったとき / Kyouto no 
furuhonya ni itta toki). Dan karena "ketika pergi ke toko buku bekas di Kyoto" merupakan unsur dalam bagian yang ditegaskan（主張される部分の範囲 / shuchou sareru bubun no hani) atau disebut dengan lingkupan yang ditegaskan (主張の スコープ / shuchou no sukoopu) maka ia dapan menjadi fokus yang ditegaskan (主張 の焦点 / shuchou no shouten).

Sebagai tambahan, Masuoka menjelaskan apabila posisi ungkapan waktu yang digayuti oleh partikel $(-n i)$ berada dekat dengan topik kalimat, dan apabila setelah ungkapan waktu yang digayuti oleh partikel (-ni) terdapat tanda koma, maka fungsi ungkapan waktu tersebut berubah menjadi komponen keadaan (状況成分 / joukyou seibun) yang memaparkan informasi baru sebagai latar waktu terjadinya peristiwa.

Selai itu, konstruksi kalimat $\mathrm{P}$ toki ni Q, digunakan untuk memberitakan terjadinya peristiwa yang hanya terjadi satu kali, seperti pada kalimat di bawah ini.

(10) きのう、ちょうど夕飯を食べ終

わったときに、かなり激しい地 震がありました。

(Teramura, 1999 : 151)

Kinou,/ choudo /yuuhan / o / tabeowatta / toki ni, / kanari /hageshii /jishin/ga/

Kemarin/ tepat / makan malam / PO / setelah makan / KT PW, / lumayan / hebat / gempa / PS /

arimashita.

ada

'Kemarin, tepat setelah makan $\underline{\text { malam, }}$, terjadi gempa yang lumayan hebat.'

\subsubsection{Konstruksi P Toki (ni) wa Q}

Konstruksi $\mathrm{P}$ toki (ni) wa $\mathrm{Q}$ digunakan saat $\mathrm{P}$ toki $\mathrm{Q}$ menyatakan peraturan yang bersifat umum. Misalnya pada kalimat berikut ini.

（11）火事や地震が起こったときには、 エレベータを使用しないで下さい。

(Sunagawa, 1998 : 324)
Kaji /ya/jishin /ga/okotta/toki

ni wa, lerebeeta /o /shiyou shinaide kudasai.

Kebakaran / dan / gempa / PS / terjadi / KT PW PT, / elevator /PO / jangan gunakan

'Ketika terjadi kebakaran dan

gempa, jangan gunakan elevator!'

Kalimat (11) menyatakan suatu peraturan bahwa setiap waktu 'ketika kebakaran dan gempa terjadi' (火事や地震が起こったと きには / kaji ya jishin ga okotta toki ni wa) 、'jangan gunakan elevator.' (エレベータ を使用しないで下さい / erebeeta o shiyou shinaide kudasai).

Pernyataan Sunagawa di atas juga diperkuat oleh Teramura (1999:152) yang menyatakan bahwa konstruksi P toki (ni) wa Q merupakan jawaban atas pertanyaan "pada waktu P, kejadian apakah yang terjadi ?" "bagaimanakah keadaannya" atau "umumnya pada saat $\mathrm{P}$, situasi akan menjadi bagaimana?"

Tetapi apabila konstruksi ini terdapat pada peristiwa yang terjadi hanya satu kali, maka predikat Q menyatakan keadaan.

Merujuk pada Teramura (1999:153), konstruksi $\mathrm{P}$ toki ni wa $\mathrm{Q}$ dan $\mathrm{P}$ toki wa $\mathrm{Q}$ dianggap sama. Meskipun konstruksi $\mathrm{P}$ toki ni wa $\mathrm{Q}$ dan $\mathrm{P}$ toki wa $\mathrm{Q}$ ada yang tidak dapat saling menyulih, namun demikian ungkapan waktu dengan gayutan partikel ($n i w a)$ dan (-wa) sama-sama menyatakan komponen keadaan (状況成分 / joukyou seibun).

Partikel (-wa) mempunyai fungsi gramatikal sebagai partikel pemarkah topik. Sebagai partikel pemarkah topik partikel (wa) menandai nomina, frasa nominal, atau klausa nominal dan sebagai konsekuensinya, nomina yang ditandai oleh partikel $(-w a)$ berfungsi sebagai topik dalam kalimat. Sebagai topik, frasa nominal yang digayuti oleh partikel pemarkah topik (-wa) mewatasi ruang lingkup (範囲 / hani) yang akan dipaparkan dalam kalimat. Dan pada konstruksi $\mathrm{P}$ toki (ni) wa $\mathrm{Q}$ ini, setelah partikel pemarkah topik $(-w a)$ diuraikan deskripsi mengenai topik tersebut.

Selain itu, sebagai partikel pemarkah topik (-wa) mempunyai fungsi sebagai pembanding. Teramura (1991) menyatakan 
bahwa pada kalimat yang dimarkahi oleh partikel (-wa) mempunyai makna tersurat ( コト的意味 / kototeki imi) dan makna tersirat (影的意味 / kageteki imi). Bahasa Jepang adalah bahasa yang bersifat pragmatis, namun demikian makna dalam kalimat juga dapat dikaji dari sisi semantiknya. Konsep makna tersurat dan tersirat ini mengacu pada makna semantik yang terdapat di dalam kalimat, yaitu makna yang didefinisikan semata-mata sebagai ciri ungkapan-ungkapan dalam bahasa tertentu dan tentu tidak terlepas dari sifat kepragmatisannya. Sifat semacam ini disebut oleh Leech (1993) sebagai semantisisme. Seperti terlihat pada kalimat berikut ini.

(12) 夕飯を食べおわったときは、外 はもう真暗だつた。 (Teramura, 1999:152)

Yuuhan /o / tabeowatta / toki $\underline{\boldsymbol{w a}}$, / soto / wa / mou / makkura / data.

Makan malam / PO / selesai makan / KT-PT / luar / PT / sudah / gelap gulita / Kop.

'Selesai makan malam, di luar sudah gelap gulita.

Pada kalimat (10) terdapat makna tersurat dan tersirat seperti berikut ini,

(12)a. 夕飯を食べおわったときは、 外はもう真暗だった。(コト)

(Teramura, 1999:152)

Yuuhan /o /tabeowatta/toki

wa, / soto / wa / mou /makkura / data.

Makan malam / PO / selesai makan / KTPT / luar / PT / sudah / gelap gulita /Kop.

'Setelah selesai makan malam, di luar sudah gelap gulita. (makna tersurat)

(12)b. 夕飯を食べおわるときは、外 はまだ明るかっただ。(影)

Yuuhan / o/tabeowaru / toki wa, / soto / wa / mou /akarukatta / $\overline{d a}$.

Makan malam / PO / selesai makan / KTPT / luar / PT / masih / terang / Kop.

'Sebelum selesai makan, di luar masih terang. (makna tersirat)
Dari keterangan di atas dapat dipahami bahwa gayutan partikel (-wa) menyiratkan makna perbandingan. Pada kalimat (12) terdapat perbandingan bahwa 'sampai baru saja langitnya masih terang', namun 'sekarang di luar sudah gelap',

Selain itu, bila Q merupakan ekspresi yang menyatakan keadaan dan mempunyai predikat berkategori adjektiva atau verba keadaan -te iru, maka konstruksi $\mathrm{P}$ toki (ni) wa $\mathrm{Q}$ bisa digunakan.

\section{SIMPULAN}

Berdasarkan pembahasan di atas, dapat ditarik simpulan bahwa meskipun sama-sama memiliki fungsi menghubungkan kalimat majemuk dengan hubungan waktu bersamaan, konjungsi toki, toki (ni), dan toki (ni) wa memiliki kekhasan dalam penggunaannya dalam kalimat sebagai berikut.

1) Konstruksi P Toki $Q$

- Konstruksi $\mathrm{P}$ toki Q paling tepat digunakan pada kalimat yang menyatakan kemunculan (発見 / hakken) dimana pertama-tama diungkapkan peristiwa $\mathrm{P}$, kemudian dipaparkan peristiwa $\mathrm{Q}$ sebagai peristiwa yang terjadi mengikuti peristiwa $\mathrm{P}$ tersebut. Dalam hal ini baik $\mathrm{P}$ maupun $\mathrm{Q}$ merupakan informasi baru.

- Konstruksi ini merupakan konstruksi yang paling netral, dimana kalimat dengan konjungsi toki (ni) dan toki (ni) wa dapat disulih dengan toki.

2) Konstruksi P Toki (ni) Q

- Konstruksi ini ini paling tepat digunakan untuk menyatakan peristiwa yang terjadinya hanya satu kali.

- Konstruksi P toki (ni) Q ini merupakan jawaban atas pertanyaan 'kapan peristiwa Q terjadi'(Q⿱中一う事態がいつ起こ ったか / $Q$ to itu jitai ga itsu okottaka), dimana Q merupakan informasi lama. 
3) Konstruksi P toki (ni) wa $\mathrm{Q}$

- Konstruksi ini paling tepat digunakan untuk menyatakan peraturan yang bersifat umum dan kebiasaan yang bersifat pengulangan.

- Apabila menyatakan peristiwa yang terjadi hanya satu kali, predikat Q menyatakan keadaan .

- Konstruksi P toki (ni) wa Q merupakan jawaban atas pertanyaan 'Pada waktu $\mathrm{P}$, terjadi hal seperti apa, bagaimana keadaannya ?' ( P というときに 、どういうことがあったか、ど ういう状態だったか / P to iu toki ni dou iu koto ga atta ka, dou iu joutai datta $\mathrm{ka}$ ) atau 'secara umum ketika P, menjadi bagaimana' (一 般に P というとき、どうなるか I ippan ni P to iu toki, dou naru ka)

\section{DAFTAR SINGKATAN}

PT : Pemarkah Topik

PS : Pemarkah Subjek

PO : Pemarkah Objek

PW : Pemarkah Waktu

PNN : Pemarkah Nomina dengan

Nomina

KT : Konjungsi Toki

\section{DAFTAR PUSTAKA}

Chaer, Abdul. 2007. Linguistik Umum.Jakarta : Rineka Cipta. .2009. Sintaksis ; Pendekatan Proses. Jakarta : Rineka Cipta.

Iori, Isao et al. 2003. Chuujoukyuu o Oshieru Hito no Tame no Nihongo Handobukku. Tokyo : Suriiee Nettowaaku.

Masuoka, Takahashi dan Takubo Yukinori. 1999. Kiso Nihongo Bunpou. Tokyo : Kurushio Shuppan.

Nitta, Yoshio et al. 1997. Fukubun no Kenkyuu (Jou) : Nitta Yoshio Hen. Tokyo : Kuroshio Shuppan.
. 2007. Gendai Nihongo Bunpou Dai $5 \mathrm{Bu}$ : Tensu; Dai 6 $\mathrm{Bu}$ : Asupekuto; Dai $7 \mathrm{Bu}$ : Kouhi . Tokyo : Kurushio Shuppan.

Teramura, Hideo. 1999. Teramura Hideo Ronbunshuu I : Nihongo Bunpouhen. Tokyo : Kurushio Shuppan.

Sunagawa, Mariko et al. 1998. Kyoushi to Gakushuusha no Tame no Nihongo Bunkei Jiten. Tokyo : Kurushio Shuppan.

Yamada, Toshihiro. 2004. Kokugo Kyoushi Ga Shitteokitai Nihongo Bunpou. Tokyo : Kurushio Shuppan.

\section{RUJUKAN ELEKTRONIK :}

Tim Penyusun Kamus Pusat Bahasa . 2008. Kamus Besar Bahasa Indonesia edisi III. Jakarta : Balai Pustaka. Melalui ,< http://bahasa.kemdiknas.go.id/kbbi> 